\title{
A permanência do Regionalismo na literatura brasileira contemporânea
}

\author{
The permanence of Regionalism in Brazilian contemporary literature \\ La permanencia del Regionalismo en la literatura brasileña contemporánea \\ André Tessaro Pelinser ${ }^{*}$ \\ Márcio Miranda Alves ${ }^{* *}$
}

\section{Resumo}

Este artigo analisa a permanência de marcas do Regionalismo na prosa da literatura brasileira contemporânea. Considerado ultrapassado pela crítica literária e renegado pelos escritores, o Regionalismo entrou para a história da literatura brasileira como sinônimo de arte de baixa qualidade estética. No entanto, percebe-se que os temas regionais nunca deixaram de ser matéria para a narrativa ficcional brasileira, desde Guimarães Rosa, Erico Verissimo e Josué Guimarães, até Luiz Antonio de Assis Brasil, Antônio Torres e Milton Hatoum. Observa-se que a diferença entre o presente e o passado reside na ênfase dada pelos escritores ao contexto e ao espaço regionais, em um primeiro momento ufanistas em relação às particularidades da terra, e na contemporaneidade preocupados com a problematização dos contrastes culturais. Conclui-se que a literatura brasileira contemporânea deve muito à tradição regionalista, sem que isso implique questionamentos de qualidade estética, e que cabe à crítica investigar os temas e as formas da narrativa como chaves de interpretação para problemas históricos que perduram.

Palavras-chave: Regionalismo, região, literatura brasileira contemporânea.

\begin{abstract}
This article analyzes traces of Regionalism in contemporary Brazilian fiction. Regarded as outdated by literary critics and disavowed by writers, Regionalism, within the history of Brazilian Literature, has long been considered to be of low aesthetic value. Nevertheless, regional themes have never ceased to appear in Brazilian fictional narrative, from Guimarães Rosa, Erico Verissimo, and Josué Guimarães, to Luiz Antonio de Assis Brasil, Antônio Torres, and Milton Hatoum. The difference between the past and present Regionalism resides in the emphasis writers assign to regional context and space: when it first appeared there was a nationalist preoccupation with regional particularities, and, in its contemporary manifestation, there appears a concern for problematizing cultural contrasts. Thus, one can conclude that contemporary Brazilian literature is indebted to the regionalist tradition, though this should not question its aesthetic value, and that literary criticism is responsible for treating
\end{abstract}

\begin{abstract}
Resumen
Este artículo analiza la permanencia de marcas de Regionalismo en la prosa de la literatura brasileña contemporánea. Considerado superado por la crítica literaria y renegado por los escritores, el Regionalismo entró a la historia de la literatura brasileña como sinónimo de arte de baja calidad estética. Sin embargo, se percibe que los temas regionales nunca dejaron de ser materia para la narrativa ficcional brasileña, desde Guimarães Rosa, Erico Verissimo y Josué Guimarães, hasta Luiz Antonio de Assis Brasil, Antônio Torres y Milton Hatoum. Se observa que la diferencia entre el presente y el pasado reside en el énfasis dado por los escritores al contexto y al espacio regionales, en un primer momento orgullosos de las particularidades regionales, y en la contemporaneidad preocupados por la problematización de los contrastes culturales. Se concluye que la literatura brasileña contemporánea debe mucho a la tradición regionalista, sin que ello implique cuestionamientos de calidad estética, y que corresponde a la crítica investigar los temas y las formas de la narrativa como claves de
\end{abstract}

\footnotetext{
* Universidade Federal do Rio Grande do Norte (UFRN), Currais Novos, RN, Brasil. (Dorcid.org/0000-0001-9756-0116. E-mail: andre.pelinser@gmail.com

** Universidade de Caxias do Sul (UCS), Caxias do Sul, RS, Brasil. (Dorcid.org/0000-0001-6455-7332. E-mail: mmalves2@ucs.br
} 
theme and narrative form as interpretative keys of persisting historical problems.

Keywords: Regionalism, region, contemporary Brazilian literature. interpretación de problemas históricos que perduran.

Palabras-clave: Regionalismo, región, literatura brasileña contemporánea.

\section{Percursos da crítica}

Se a questão regional faz parte da história brasileira, é necessário reconhecer que as alterações que sua abordagem vem sofrendo mostram-se lentas em comparação à importância do tema, de modo que em termos teóricos e literários parecem ainda insuficientes. Apenas mais recentemente a matéria começou a ser encarada de forma detida nos estudos literários. Em estudo publicado em 2003, o crítico, tradutor e escritor José Clemente Pozenato (2003, p. 149) afirma que a ideia de região transitou, nos últimos vinte anos, de uma visão negativa para uma ao menos positiva. A partir desse estudo, poderíamos situar essa transição na década de 1980. De fato, são da década anterior alguns trabalhos do próprio Pozenato ${ }^{1}$ e de Ligia Chiappini ${ }^{2}$ a respeito do Regionalismo, os quais analisaram o tema sob novas perspectivas e certamente contribuíram para uma mudança de avaliação. No entanto, o autor parece, talvez, otimista demais ao sustentar que "antes era preciso demonstrar que o regionalismo não consistia numa visão estreita do processo social, em qualquer de suas dimensões", e que, "hoje, a percepção das relações regionais é vista como um modo adequado de entender como funciona, ou pode funcionar, o processo de mundialização de todas as relações humanas" (2003, p. 149).

No que se refere à arte literária, a regionalidade ${ }^{3}$ de certas obras e autores segue causando dificuldade aos críticos, uma vez que não são raras as avaliações que atrelam argumentos sobre o resultado estético dos textos a problemas identificados no nível do conteúdo. Exemplo eloquente da permanência do problema é a obra de Milton Hatoum: enquanto Eurídice Figueiredo traça relações possíveis entre seus textos e uma tradição regionalista vista sob a óptica do contemporâneo (Figueiredo, 2013, p. 44-45), Allison Leão parte das reflexões de Tânia Pellegrini presentes em Milton Hatoum e o regionalismo revisitado para problematizar e refutar a vinculação do escritor a essa vertente (Leão, 2011). O próprio escritor, por sua vez, rechaça essas relações, dizendo que tem tentado "evitar não apenas o exotismo, como também o regionalismo, que, muitas vezes, pode tornar-se uma camisa de força, uma forma de inscrever o texto numa área geográfica" (Marcondes, 2004). A seu ver, todavia, os traços de localismo e das circunstâncias históricas estão sempre presentes na obra, visto que o escritor estaria sempre rondando suas origens. Disso se infere que o incômodo de Hatoum não é com os elementos abarcados pelo Regionalismo, pois estes ele assume como essenciais à obra, mas com a própria categoria - com o rótulo -, o que pode se explicar pelo peso negativo que possui e pelo quanto pode concorrer para a perda de capital literário ainda hoje. Em suma, o autor reivindica abrangência, mas seu desconforto personifica um problema quase tão tradicional quanto a própria historiografia literária brasileira.

O processo de formação por que passaram as letras brasileiras, se examinado sob esse viés, fornece importantes indícios para explicar a situação presente, uma vez que o problema representado pela matriz regionalista deriva das discussões a respeito da nacionalidade e das obras gestadas pelo Romantismo. ${ }^{4} \mathrm{O}$ repertório crítico consolidado desde então paulatinamente associou a ideia de região à pecha de tacanho, pequeno e culturalmente inferior, contaminando tudo o que a ela se vincula. Cabe, hoje, indagar em que medida essa ordem de fatores interfere no julgamento do que é capaz de fornecer uma arte que se defina como regionalista. É essencial

\footnotetext{
${ }^{1}$ Seu ensaio $O$ regional e o universal na literatura gaúcha, agraciado com menção honrosa em concurso promovido pelo Instituto Estadual do Livro, foi publicado em 1974, com elogios de Guilhermino Cesar.

${ }^{2}$ A autora publica Modernismo no Rio Grande do Sul: materiais para seu estudo e Regionalismo e Modernismo: o caso gaúcho em 1972 e 1978, respectivamente.

${ }^{3}$ Entendida aqui como "particularidades culturais de um espaço regionalizado ou que se regionaliza" (Arendt, 2015, p. 115).

${ }^{4}$ Para uma discussão historiográfica a respeito do tema, ver Pelinser (2015).
} 
questionar até que ponto um autor rechaça a marcação pela ideia de Regionalismo por conta dos preconceitos atrelados a essa vertente. Do contrário, deve-se assumir que falar daquilo que está à margem dos centros culturais implica uma necessária perda de qualidade artística.

Afinal, se como aponta Pozenato, nas últimas décadas a ideia de região tem transitado de uma visão negativa para uma pelo menos positiva, parece evidente que esse trânsito ainda não se deu no campo literário, que segue atrelando à noção de Regionalismo uma concepção reduzida do fazer artístico, segundo a qual a qualidade da obra é quase que imediatamente determinada pela estreiteza do objeto do qual ela se ocupa. Essa ideia, que não está desenvolvida e registrada dessa forma, mas é assim praticada, pode ser sintetizada na seguinte equação proposta por Fischer (2007, p. 134): "cidade grande + modernização + vanguarda = arte verdadeira; sem qualquer um desses itens, temos arte velha, irrelevante, desprezível, merecedora no máximo de uma nota de pé de página". Para esse autor, são as "idealidades" que impedem uma melhor visibilidade do Regionalismo, que deveria ser submetido a "uma leitura mais histórica, a uma leitura rigorosamente materialista". Justamente porque isso não acontece, Fischer defende que a "idealidade (negativa)" chamada Regionalismo deveria ser pura e simplesmente "varrida para a lata de lixo do pensamento crítico" (Fischer, 2007, p. 138).

No entanto, como não se pode minimizar a permanência da matriz crítica que considera o Regionalismo como uma opção literária necessariamente portadora de limitações, antes de descartar de todo a categoria de análise, talvez seja proveitoso examinar as linhas de força desse debate. Ele não ocorre ao acaso, na medida em que leituras nesse sentido remontam ao século XIX, como demonstra Lajolo (1998), e perpassam todo o século XX, sendo reafirmadas de tempos em tempos por críticos como Machado de Assis, Alceu Amoroso Lima, Lúcia Miguel Pereira, Antonio Candido e Alfredo Bosi, entre outros, seja de forma explícita ou por meio de preâmbulos que levam a uma mesma conclusão. Por um procedimento que toma as falhas de obras individuais por pertencentes a toda uma vertente, estendem-se as críticas a tal ponto que obras de qualidade não podem ser vinculadas à corrente regionalista. É o que se nota em texto de julho de 2013 publicado na seção Literatura da Revista Bravo!, no qual o autor indaga já na chamada à leitura, logo abaixo do título, se "Ainda faz sentido classificar a obra de Graciliano Ramos e de outros escritores nordestinos como regionalista?" (Gama, 2013).

Para defender a qualidade artística da obra de Graciliano Ramos e de outros autores nordestinos, sustentando que o chamado "surto nordestino" é na verdade muito mais do que um momento passageiro da história literária brasileira, Rinaldo Gama recorre a críticos e escritores reconhecidos e questiona o rótulo "regionalista" a estes imposto. Para o autor, a afirmação da inegável qualidade de Graciliano Ramos parece passar por sua desvinculação da corrente, já que "Depois de seu romance de estreia, Graciliano Ramos lançaria apenas três outros livros nesse gênero - São Bernardo (1934), Angústia (1936) e Vidas Secas (1938) -, que, no entanto, representariam o ponto alto do 'surto nordestino' e comprovariam a vocação do autor para além do regionalismo" (Gama, 2013).

Do mesmo modo, Gama assinala a opinião de autores contemporâneos, para quem a afiliação regionalista é ainda mais incômoda, sinônimo de interesses e alcances reduzidos:

“No caso de alguns escritores, principalmente no de José Lins do Rego, o rótulo 'regionalista' faz sentido porque ele se aplica a nomes que seguiram a receita do sociólogo Gilberto Freyre no Manifesto de 1926, o qual defendia que a ficção e até a poesia deviam registrar, acima de tudo, traços da cultura regional, com alguma coisa de estética. Ou seja, uma literatura sociológica e antropológica, sem grandes compromissos com a arte - um equívoco enorme", argumenta o ficcionista pernambucano Raimundo Carrero, autor de A minha alma é irmã de Deus. "A crítica tem mania de pôr esse rótulo em todo escritor nordestino. Nunca fui regionalista. Não copio vidas, invento vidas, mesmo a partir da minha região", afirma Carrero, que ressalta sua identificação com o paraibano Ariano Suassuna e o Movimento Armorial, "cuja preocupação maior é a estética, tomando o regional apenas como metáfora" (Gama, 2013, s.p.).

Já Ronaldo Correia de Brito, cearense radicado em Recife e autor de Galileia, manifesta opinião levemente diversa, visto que, para esse autor, 
o critério regional não pode ser redutor porque a paisagem, o lugar são, muitas vezes, artifícios para o ficcionista tratar de questões metafísicas, que dizem respeito a todos os homens, de qualquer região. A geografia que conheço, onde nasci e vivo, é sempre a minha referência para trás, a memória a que recorro mesmo quando a história se passa em Nova York ou Fez (Brito apud Gama, 2013, s.p.).

Milton Hatoum, como mencionado, demonstra desconforto em relação à vertente, à qual foi algumas vezes associado:

O amazonense Milton Hatoum, encarregado da conferência de abertura da Flip sobre Graciliano - num curioso contraponto entre um autor criado sob o signo das águas e outro inspirado no território da seca -, considera não apenas extemporânea como inadequada a abordagem regionalista. "Há tempos essa expressão foi usada nos Estados Unidos para nomear a literatura do sul. Ironicamente, William Faulkner se tornou um dos maiores autores norte-americanos do século passado. Algo semelhante aconteceu aqui. Mas o ponto central da literatura não é a origem do escritor nem o lugar onde ocorre a narrativa e sim a linguagem; por isso Graciliano Ramos foi grande", acredita (Gama, 2013, s.p.).

Nesse caso específico, chama atenção a "ironia" de Faulkner ter se tornado um dos maiores autores dos Estados Unidos, ao mesmo tempo que sua obra recebia o malfadado rótulo de regionalista. Em vez de "ironia", esse exemplo deveria demonstrar justamente a imprecisão que é considerar tudo aquilo que se refere à região como algo inevitavelmente menor. A ironia, na verdade, encontra-se na reprovação de Hatoum ao "regionalismo" valendo-se de um exemplo comprobatório da qualidade que pode ter qualquer peça de arte, esteja ela filiada aos elementos e temas de uma região ou não, uma vez que, como diz o próprio autor na sequência, trata-se de linguagem.

Não obstante, a julgar pelos estudos de Ligia Chiappini, a permanência de traços regionalistas na ficção contemporânea não deveria surpreender. A autora afirma ter, ao longo de suas investigações sobre o regionalismo na América e na Europa, confirmado a suspeita de que esse fenômeno, sempre considerado ultrapassado pela crítica literária brasileira, não só continuava vivo em 1995, quando da publicação de seu texto, como havia se tornado tema de pesquisas bastante atuais, "ganhando uma amplitude maior na intersecção dos estudos literários e artísticos, históricos e etnológicos" (Chiappini, 1995, p. 153). Nesse trabalho, Chiappini procura "problematizar juízos críticos estereotipados que generalizam para a tendência como um todo as limitações estéticas e ideológicas da maior parte, reconheço, das obras que o regionalismo tem produzido" (Chiappini, 1995, p. 154). Afinal, não seria esse pendor o responsável pelo desconforto de Milton Hatoum, um escritor contemporâneo, ao ver sua obra ligada a tal tradição? Do mesmo modo que essa atitude dificulta o exame da obra do escritor amazonense, cria empecilhos às pesquisas sobre o legado de outros grandes nomes, como João Guimarães Rosa.

Walnice Nogueira Galvão revela que a correspondência privada de Guimarães Rosa registra a repulsa do mineiro por algumas das características da literatura que lhe era contemporânea e que vinha dominando o cenário nacional, o que incluía as vertentes regionalista e espiritualista. Embora não seja possível saber exatamente a quais escritores Guimarães Rosa se refere nas cartas, uma vez que os nomes estão censurados, para ele a literatura brasileira, "com poucas exceções, é um valor negativo, um cocô de cachorro no tapete de um salão" (Galvão, 2008, p. 115). É preciso ressaltar que essa opinião de Guimarães Rosa, destinada a um tio, surge justamente no auge do embate entre o "Regionalismo de 30" e o romance espiritualista, com predomínio daquele sobre este, quando uma parte significativa da produção literária tem nas coisas do ambiente rural o tema preferencial para a ficção. A estreia de Rosa, nesse contexto, acaba fazendo surgir "um libelo contra a má literatura" (Galvão, 2008, p. 113), o que na prática vai reforçar os argumentos, por parte da crítica, de que existe incompatibilidade entre boa literatura e temas atrelados ao campo. Embora a ficção de Guimarães Rosa abarque temas e espaços comumente associados ao Regionalismo, por apresentar um jeito de escrever inédito e de alto nível o autor seria alçado à condição de "universal", enquanto aqueles que não atingiram o mesmo padrão estético são relegados à posição de "regional". Desde então, o legado de Guimarães Rosa para a literatura contemporânea talvez esteja encoberto pelo estigma atrelado à tradição regionalista. 
No que se refere ao Regionalismo literário brasileiro, parece haver uma resistência em considerá-lo participante ativo dos processos de formação e de consolidação de uma tradição. Juliana Santini aponta a lacuna presente nos estudos literários referentes a essa vertente no período posterior ao chamado ciclo nordestino de 1930 e destaca a crítica de Ligia Chiappini sobre a insuficiência do conceito de "consciência do subdesenvolvimento" empregado por Antonio Candido para justificar a presença do Regionalismo nas letras brasileiras. Santini sustenta que embora Chiappini "reafirme essa necessidade de reinterpretação dos caminhos trilhados pela literatura regionalista após o ciclo nordestino, a autora deixa aberta a questão, restando menos uma solução do que uma interrogação". Em sua acepção, um dos méritos de Chiappini "é lançar um desafio que chama a atenção para a urgência de encontrar um lugar para essa produção literária, começando ainda pelo empreendimento de situar a obra de Guimarães Rosa em relação ao regionalismo literário brasileiro" (Santini, 2011, p. 79).

Considerada a posição canônica ocupada pelo escritor mineiro, instaura-se um problema para situá-lo em relação a uma tradição menosprezada como o Regionalismo. Para Santini, a própria

possibilidade de permanência do regionalismo na literatura brasileira produzida depois da década de 30 do século $X X$ permanece em suspenso, sem que a crítica literária tenha atado a essa lacuna um fio que preencha ou simplesmente a coloque como incompatível, de modo que parece não haver um consenso - por vezes, nem sequer uma discussão - a respeito do problema, que se torna ainda mais abrangente se forem levadas em consideração obras produzidas posteriormente ao contexto em que se insere Guimarães Rosa, como o trabalho de José Cândido de Carvalho ou, mais recentemente, de autores como Francisco J. C. Dantas, Milton Hatoum e Ronaldo Correia de Brito (Santini, 2011, p. 79).

O problema é que, como bem aponta Ygor Raduy (2006, p. 73), se em um primeiro momento é revolucionário o modo de representação do regional sugerido por Guimarães Rosa, logo ele é legitimado pela crítica e inserido no cânone literário, tornando-se clássico por ser "universal". Nesse processo, a novidade é enrijecida em padrão e subsumida pelo discurso historiográfico, que procura apreendê-la a partir das categorias existentes e com isso por vezes falha em perceber os processos de transformação da tradição. Assim, parte da renovação proposta pela ficção de Guimarães Rosa tem quedado silenciada nos estudos críticos, que ainda hoje têm tido dificuldades para identificar as ressonâncias da obra do escritor mineiro na literatura de seus pares, mesmo quando estes a anunciam em entrevistas e congressos, o que tem mascarado certas mutações da tradição regionalista.

Curiosamente, escritores além-fronteira não manifestam o mesmo ressentimento ao reconhecerem sua dívida com Guimarães Rosa. O moçambicano Mia Couto, por exemplo, um dos principais expoentes da literatura ocidental contemporânea, já enfatizou a influência de Rosa sobre a sua prosa poética, mais precisamente por conta da oralidade do sertão transposta para a narrativa ficcional. Mia Couto conta que foi apresentado à obra de Guimarães Rosa - inicialmente o volume de contos Primeiras estórias - por Luandino Vieira, escritor angolano que já havia declarado ter sido influenciado pelo mineiro:

Aquilo foi um abalo sísmico na minha alma, porque ali estava o que eu e outros estávamos procurando. Havia ali não só uma relação com a língua, mas também com outras coisas que estão para além dela, uma tentação de criar na linguagem um universo próprio, como se a linguagem se apropriasse da história, da geografia, criando outra realidade. E essa outra realidade também era importante para nós, que estávamos vivendo a lógica de um estado centralizador, que esmagava as lógicas rurais, esse mundo do sertão, que não é da ordem da geografia, mas da soma de várias culturas. A leitura de Guimarães Rosa foi para mim como um rasgão. Grande sertão: veredas é aquele livro ao qual se regressa constantemente, capaz de retratar um mundo inteiro (Couto, 2010).

A partir de testemunhos como esse, não se precisa de muito esforço para concluir que o reconhecimento da influência de Guimarães Rosa sobre escritores de outros países, nesse caso africanos, tem a ver justamente com o fato de, nesses países, a "questão" do regional trilhar por outras veredas. Ou seja, até onde se sabe a história da literatura nesses lugares não reconhece o temário regional como algo identificado com uma obra de suposta qualidade inferior e, por isso, não existe 
constrangimento entre os escritores de assumirem certa identificação com um autor notadamente regionalista. Evidentemente as literaturas africanas refletem processos históricos diferentes, e lançar olhares nesse sentido daria um novo rumo para a discussão, o que não vem ao caso agora.

O que importa compreender, para a análise aqui proposta, é que o discurso crítico, desde o lançamento de Sagarana, em 1946, manifesta uma relação conturbada com as características comumente associadas ao Regionalismo, ora reconhecendo, ora negando sua presença na ficção rosiana. Em vez de fomentar novas percepções críticas acerca da literatura produzida com base em espaços regionais, a obra de Guimarães Rosa parece ter contribuído, involuntariamente, para a consolidação de matrizes de pensamento que negam ao regional o estatuto literário. Na fortuna crítica do autor, merece destaque a criação de um paradigma de interpretação interessado na "superação" do regional, presente sobretudo em dois textos de Antonio Candido: na primeira resenha de Sagarana, de 1946, e no ensaio Literatura e subdesenvolvimento, de 1970. Nesses dois momentos, instaura-se e reforça-se a ideia de que a boa ficção - e a literatura brasileira em geral - precisa "superar" o regional para então alçar-se ao "universal" ${ }^{5}$

\section{Percursos da literatura}

Passando, em princípio, ao largo desse debate, em texto que discorre sobre três romances de Milton Hatoum e mapeia uma série de ressonâncias de outras obras na escrita desse autor, Maria Zilda Cury assinala uma das mais importantes funções da arte em geral, da literatura mais especificamente: "Através de sua estranheza e de seu deslocamento, sua ficção abre espaço e faz com que se ouçam vozes nativas, reprimidas, as vozes daqueles considerados como afásicos culturais" (Cury, 2009, p. 46). A autora recorda, ainda, que a autobiografia de Edward Said, intitulada Out of place, defende que o intelectual deve falar a partir da margem da produção das ideias, de forma que possa evitar o pensamento central e levar em conta os marginalizados da sociedade (Cury, 2009, p. 49), e situa nessa característica o triunfo de Hatoum. Destaca sua capacidade de "Olhar o outro, sabendo-se não ser o outro. Sentir com o outro, sabendo-se não ser o outro. Responsabilizar-se pelo outro, radicalmente, como quer ainda Levinas, responsabilidade como superação ética da percepção da alteridade" (Cury, 2009, p. 59).

Então, é interessante que precisamente esse autor protagonize uma relação tão problemática com o Regionalismo. Afinal, pode-se verificar em sua obra certos traços de localismo, uma espécie de "localização excessiva" das tramas que permite sua inserção em uma tradição desventurada, ao mesmo tempo que se identifica na visão de mundo veiculada pelos seus textos uma capacidade singular de dar voz ao outro. Em praticamente todas as suas obras, sejam romances ou contos, a valorização do espaço e seus elementos regionais indicam a preocupação de criar um universo ficcional em que homem e meio estão intimamente ligados, e no qual as idiossincrasias daquele não raro são determinadas pela sua percepção deste. Essa relação, assim, pode ora indicar um sentimento de identificação entre ambos, ora um sentimento de rejeição. O resultado aponta justamente para as contradições entre mundos que se contrapõem, como atraso e modernidade, floresta e cidade, conservadorismo e vanguardismo, etc.

Um sintoma dessas relações pode-se encontrar nos personagens Mundo e Arana, em Cinzas do norte. Ambos são artistas plásticos; o primeiro, um aprendiz do segundo. O conformista Arana investe na carreira da arte decorativa para enfeitar os lares da classe média alta com temas regionais da Amazônia, destacando a exuberância da flora e da fauna. O rebelde Mundo, engajado nas causas sociais e inconformado com as mazelas da população, prefere a arte de combate, pensada e produzida para causar impacto e incômodo junto aos mandatários. Os motivos da arte de Mundo não deixam de ser regionais, pois também lidam com problemas locais, mas se constroem em modelos críticos e não ufanistas. Essa diferença entre os dois, no entanto, não nasce do acaso. Mundo passa as férias com a família no Rio de Janeiro, onde conhece outros artistas, novas formas

\footnotetext{
${ }^{5}$ Para uma discussão detalhada sobre o lugar ocupado por Guimarães Rosa na discussão sobre o Regionalismo literário brasileiro e sobre como sua recepção crítica acabou por aprofundar o problema, ver Pelinser (2017).
} 
de expressão e uma visão da sociedade que se choca com a Manaus de Arana. Em uma conversa com o amigo Lavo, Mundo comenta sobre o mestre Arana:

"Não é mais o mesmo", disse, com aspereza. "Aliás, nós não somos mais os mesmos, Lavo. $\mathrm{O}$ ateliê dele é uma fábrica de quadros e esculturas. Arana renegou até aquela jaula queimada cheia de ossos e capim seco... Dizia que era uma obra muito crítica, mas hoje acha que é fútil. Uma fase experimental, já passou... Falou assim mesmo, e ainda riu. Arana virou um reles comerciante da arte. Quis que ele repetisse tudo sobre o meu projeto. Então: por que o Campo de cruzes era apenas uma provocação? Não respondeu. É um cara medroso demais. Agora ele decora gabinetes, manda presentes a oficiais e políticos... E não perdoa o teu tio. Vai lá no ateliê... Ele não esconde o ódio a Ranulfo" (Hatoum, 2005, p. 163-164).

O projeto "Campo de cruzes" a que se refere Mundo consiste na instalação de 80 cruzes de madeira queimada no conjunto habitacional Novo Eldorado, em protesto contra a morte de um amigo durante atividades do Colégio Militar. Considerado a maior obra urbanística do prefeito Zanda, coronel do Exército que pretende modernizar Manaus com uma reforma urbana, o residencial Novo Eldorado consiste em um conjunto de casas inacabadas e sem fossas, água, luz ou recolhimento de lixo, espalhadas por ruas enlameadas e distantes do centro urbano. "Os moradores do Novo Eldorado eram prisioneiros em sua própria cidade" (Hatoum, 2005, p. 148).

Essas contraposições entre os artistas Mundo e Arana são sintomas da profundidade da reflexão do ambiente regional em Milton Hatoum. Ao opor dois projetos artísticos distintos de figuras amazonenses, o escritor sinaliza justamente as contradições inerentes ao processo de reconhecimento e aceitação do local frente ao "universal". São duas formas de encarar o lugar da região de pertencimento frente ao restante do mundo, uma fechada em torno de seu eixo e outra aberta a novas possibilidades. Enquanto um reivindica o direito de reforçar uma identidade mitificada, fornecendo aos pares o que eles buscam e estão dispostos a pagar (negociando o regional como mercadoria), o outro atua no sentido inverso, em uma luta mais árdua para esgarçar a realidade de fora para dentro. Para isso, Arana fecha-se em seu atelier em Manaus, cidade que se poderia chamar de "metrópole regional" por causa de seu afastamento geográfico em relação ao centro do país, ao passo que Mundo transita por outras metrópoles, reconhecidamente "globais" (e, por extensão, "universais"?), como Rio de Janeiro, Berlim e Londres. Em suma, as contraposições caras ao Regionalismo estão todas postas aí, apresentadas com brilhantismo formal e estético. Nesse sentido, causaria estranheza o desconforto de Milton Hatoum diante do Regionalismo, caso não personificasse um problema quase tão tradicional quanto a própria historiografia brasileira e que perdura no século XXI.

Por uma outra chave de leitura, não seria possível indagar se não seria justamente esse o papel do Regionalismo, de estar à margem e falar com e por aqueles que não têm acesso ao centro? Talvez seja lícito pensar o desenvolvimento dessa vertente das letras brasileiras a partir desse lugar marginal, levando-se em conta, é óbvio, a posição culturalmente central dos primeiros autores. Não haveria sentido defender que um homem como José de Alencar estivesse devotado a dar voz ao índio, ao gaúcho, ao sertanejo em uma perspectiva culturalista nos termos atuais. José de Alencar tinha um projeto literário bem conhecido e sua produção reflete a sociedade e a história do Brasil monárquico em busca de uma identidade própria, cujos "defeitos" de composição, quando ocorrem, "são os do tempo", como aponta Candido (2007, p. 546). Porém, talvez já seja possível pensar em outro tipo de aproximação ao objeto narrado no caso de Euclides da Cunha, partindo de um ponto de vista que sem dúvida busca registrar a atrocidade cometida contra um grupo social minoritário, regionalmente localizado e largamente desconhecido, e inscrever sua voz na história de uma nação. Nessa perspectiva, Euclides da Cunha teria feito em Os sertões o que os próprios historiadores ainda nem imaginavam, que é se debruçar sobre o particular para revelar um contexto mais amplo - o que também vai refletir na forma literária a partir do romance social de 30. Curiosamente ou não, a obra de Euclides da Cunha não costuma ser associada ao Regionalismo, embora a matéria regional seja a base que solidifica sua narrativa, e muitas vezes com uma denotação mais pessoal do que se suporia.

Do mesmo modo, no caso de Guimarães Rosa, ainda que não haja o declarado tom de denúncia, pode-se questionar em que medida a aliança de moderno e arcaico professada pelo conjunto da 
obra contribui para comunicar os dramas de uma parte do Brasil da qual uma parcela central e elitizada da sociedade só toma conhecimento quando a arte logra impactar e se inserir no imaginário. A propósito, cabe retomar um texto bastante desconhecido, mas profundamente relevante para que se compreenda o universo narrativo de Guimarães Rosa. Em Pé-duro, chapéu-decouro, publicado em jornal em 1952 e posteriormente recolhido em Ave, palavra (1970), Rosa apresenta uma profissão de fé acerca da figura do sertanejo na cultura brasileira. Ao discorrer sobre um encontro de vaqueiros no interior da Bahia, o escritor não se furta a louvá-los como espécie de símbolo nacional e sugere a necessidade de "prestigiar-lhes a fórmula etológica, o desenho biográfico, o capital magnífico de suas vivências - definindo em plano ideal a exemplar categoria humana do vaqueiro, em fim de fundá-la no corpo de nossos valores culturais" (Rosa, 2001a, p. 173). Consciente de seu tom laudatório, Guimarães Rosa acrescenta uma nota de rodapé em que se justifica, defendendo que estamos por demais "sonsos e céticos", e por medo da opinião alheia perdemos a capacidade de "admirar e louvar, ou mesmo o módico dever de reconhecer", o que lhe permite a ousadia: "se exagero, jus para o exagero" (Rosa, 2001a, p. 173).

Não surpreende, pois, que os deslizamentos entre arcaico e moderno e as superposições de sentido daí decorrentes que se verificam na ficção de Guimarães Rosa jamais privilegiem um sobre outro. Em seus textos, o mundo do sertão é reelaborado por uma prosa moderna e responsável - para retomar a ideia de Levinas referida por Cury -, dotada de profunda percepção da alteridade e fundada em uma ética incapaz de subvalorizar o sertanejo e o seu espaço. Na obra rosiana, o sertão não comparece como pano de fundo para discussão de outros temas, tampouco é figurado como interesse exótico; antes, constrói a própria estrutura das narrativas e fornece a base sobre a qual emergem múltiplos significados. Na literatura de Guimarães Rosa, enfim, a possibilidade de formular interpretações atreladas às mais diversas mitologias, à filosofia tanto ocidental como oriental, à História do Brasil, entre outras, advém da forma como uma região muito particular de Minas Gerais é ficcionalizada. Por essa chave pode-se compreender a asserção de Riobaldo, para quem "o sertão é do tamanho do mundo" (Rosa, 2001b, p. 89).

Precisamente desse ponto resulta a importância da obra de Guimarães Rosa para as modulações contemporâneas dos espaços regionais na ficção brasileira, embora a crítica literária tenha apresentado dificuldades, ao longo do tempo, para bem situá-la no conjunto da literatura nacional e de seus ciclos. De resto, a própria falta de clareza nas definições do termo Regionalismo, compreendido como tradição literária, contribui para explicar a posição ambígua do escritor mineiro quando de sua vinculação a essa vertente, como pode ser verificado na famosa entrevista a Günter Lorenz. Nela, Guimarães Rosa problematiza os conceitos de "regionalismo" e "regionalista", assegurando que não gostaria de ser considerado na Alemanha um Heimatschriftsteller, "uma vez que é para você o que corresponderia ao conceito de 'regionalista'". Porém, ao mesmo tempo, e de modo paradoxal, o autor se apresenta como "homem do sertão" e assegura estar "plenamente de acordo, quando você me situa como representante da literatura regionalista; e aqui começa o que eu já havia dito antes: é impossível separar minha biografia de minha obra" (Lorenz, 1991, p. 65-66).

Note-se que, na entrevista, o termo "regionalista" vem empregado entre aspas na primeira passagem, quando Rosa o renega, e sem aspas na segunda, quando o aceita. Isto é, a posição do escritor mostra-se ambígua e reflete a complexidade que o tema alcançou na literatura brasileira. Ademais, conquanto a discussão não estivesse no horizonte de Guimarães Rosa nestes termos, é importante destacar que Heimatschriftsteller não corresponde com exatidão à ideia de "escritor regionalista" nos termos brasileiros, mas a "escritor de/sobre a terra natal". Segundo Norbert Mecklenburg (2013, p. 179-180):

Quem pretende compreender criticamente o desenvolvimento da Literatura Sobre Terra Natal no século XX precisa, portanto, diferenciar cuidadosamente: literatura moderna que formula artisticamente o problema humano da terra natal; literatura regionalista, que trata da aldeia ou da província; literatura romântico-ideológico-agrária que, na Alemanha, representou uma corrente literária antimodernista, da virada do século até a época do Nacional-Socialismo.

Algo semelhante ocorre no Rio Grande do Sul a partir da publicação de $O$ tempo e o vento, de Erico Verissimo. Considerado pela historiografia um dos expoentes do Regionalismo de 1930, Erico 
também rejeitou a classificação de sua obra como regionalista, embora os elementos regionais relativos ao homem do campo, à terra, à paisagem e aos costumes do pampa façam parte da base temática que sustenta a sua ficção. Em seu livro de memórias, Erico admite sentir admiração por "trabalhos isolados" de autores como João Simões Lopes Neto, Darcy Azambuja, Cyro Martins e Vargas Neto, mas afirma ter procurado esquivar-se do regionalismo, segundo ele, um "gênero literário [...] limitado e, em certos casos, com um certo odor e um imobilismo anacrônico de museu" (Verissimo, 1995, p. 288). Para Erico Verissimo, a prova dessa ausência do regional em O tempo e o vento reside em seu desconhecimento do "jargão gauchesco", pois detestava a vida rural, desconhecia a vida das estâncias e não sabia andar a cavalo (Verissimo, 1995, p. 288).

Na trilogia, a "denúncia social" de 1930 transparece nos momentos de conflito, como as guerras e revoluções, justamente para confrontar os modelos literários da geração anterior, que procurava exaltar os valores de bravura e coragem do gaúcho moldado pela luta armada. Nesse processo de reescrita de um modelo identitário ancorado no mito, Erico Verissimo relativiza o ideal maniqueísta que insistia em colocar o gaúcho brasileiro em posição de confronto em relação ao estrangeiro, fosse ele castelhano ou luso-brasileiro de outras regiões do Brasil. ${ }^{6}$

Em outros momentos históricos, a narrativa do escritor gaúcho privilegia grupos sociais até então minoritários - como os imigrantes europeus -, unindo-os num presente que traduz de maneira mais sensata o processo de formação identitária da região. Nessa perspectiva, todos os novos agentes sociais são contemplados num mesmo quadro, mas algumas imagens simbólicas do passado romântico não são de todo abandonadas, passando por um processo de ressignificação para além de uma celebração ingênua. Não por acaso, a tradição do Regionalismo de Erico Verissimo - cuja temática não se resume ao campo, mas, também, à cidade em rápida transformação - tornou-se modelo quase obrigatório para os escritores gaúchos posteriores, e semelhanças relacionadas aos temas e às formas de abordagem podem ser encontradas nos conterrâneos Josué Guimarães, Luiz Antonio de Assis Brasil, Tabajara Ruas, Letícia Wierzchowski e Sérgio Faraco, entre outros, sem que esse "modelo" temático implique necessariamente literatura de menor valor.

Nos anos de 1970, Josué Guimarães refaz a saga dos imigrantes alemães no romance $A$ ferro $e$ fogo, interrompido pela morte do escritor antes que completasse o terceiro volume. À semelhança do que Erico Verissimo havia feito em relação ao processo de formação identitária do gaúcho no Continente de São Pedro, Josué concentra-se nos dramas de adaptação do estrangeiro, aquele que precisa vencer as barreiras do idioma, da cultura e da geografia em um ambiente inóspito. A solidão dos campos, os perigos dos constantes conflitos armados e o achatamento do sujeito comum frente aos movimentos históricos são apresentados de uma maneira que não deixa margem para heroísmos de qualquer natureza. A superação do meio não ocorre sem sofrimento e dor, prevalecendo um tom de denúncia que leva o leitor a enxergar o processo imigratório por um viés bem diferente daquele que apenas exalta as conquistas dos desbravadores europeus.

Apesar de haver uma inegável proximidade de forma e tema entre Josué Guimarães e Erico Verissimo, aquele sempre negou qualquer influência deste e de qualquer outro autor gaúcho. Guimarães afirma que procura empregar "uma linguagem o mais possível nacional" (Guimarães, 1988, p. 6), justamente para compensar o tanto de regional que não consegue negar em sua ficção. Para ele, bem como para Verissimo, como já foi apontado, as marcas do regional são exclusivamente uma questão linguística, ou seja, "modismos gaúchos", conforme suas palavras. Assim, o autor de A ferro e fogo luta para criar uma "linguagem nacional" que o liberte do estigma do regional (gaúcho), ao mesmo tempo que a narrativa se apresenta com muitos diálogos em

\footnotetext{
${ }^{6}$ É justo salientar que interpretações diferentes podem surgir, dependendo do viés analítico de episódios ou lances isolados da unidade da trilogia, no sentido de apontar a existência de certa "glamourização identitária" em $O$ tempo e o vento. Pesavento (2001, p. 101102), por exemplo, afirma que "Pode parecer heresia dizer que a narrativa ficcional de Erico se atrele a este viés, que coloca num passado atemporal e glamourizado o padrão de referência do Rio Grande, mas Erico é filho de seu tempo, e sua escritura é datada. Entendemos que perpassa pela sua obra o delineamento de certos valores e 'defeitos bonitos', que fazem do gaúcho um arquétipo sedutor e que dão, ao menos, uma 'compensação simbólica' para perdas reais”.
} 
alemão. Por isso, Josué Guimarães prefere vincular sua obra a Machado de Assis, Graciliano Ramos e Jorge Amado. ${ }^{7}$

Na mesma época surge para a literatura Luiz Antonio de Assis Brasil, outro escritor cujo conjunto da obra mantém pontos de contato com a tradição regionalista. Estreou em 1976, com Um quarto de légua em quadro, e desde então publicou muitos romances identificados com os temas regionais, sempre explorando as contraposições entre o homem do campo e o da cidade, atraso e modernidade, memória e esquecimento. Em suas obras, os principais personagens da história do Rio Grande do Sul estão em diálogo constante com a fábula romanesca, muitas vezes servindo de arquétipos para a representação de coronéis em meio ao processo de modernização, em uma espécie de arco que revela a ascensão e a queda de um grupo social que se projeta para a história a partir da Revolução Farroupilha (1835-1845) e sucumbe juntamente com a Revolução de 1930.

Mais recentemente, em um painel composto por O pintor de retratos (2001), A margem imóvel do rio (2003), Música perdida (2006) e Figura na sombra (2012), quatro romances agrupados sob o título Visitantes ao Sul, Assis Brasil assinala outro modo de convergência espacial. Novamente marcado pelo recurso a personalidades históricas ficcionalizadas, o conjunto de narrativas põe em cena personagens multifacetados e inapreensíveis em sua totalidade, que, construídos pela mão da ficção contemporânea, acham-se em permanente trânsito, em incessante mobilidade, não obstante habitem séculos passados. Comparecem aos enredos, com maior ou menor peso, as figuras literarizadas de Aimé Bonpland e Alexander von Humboldt, em Figura na sombra; o fotógrafo francês Félix Nadar, em O pintor de retratos; o Imperador Dom Pedro II, em A margem imóvel do rio; e os músicos José Maurício e Joaquim José de Mendanha, ambos em Música perdida. Acompanhando a trajetória desses e dos demais personagens, os textos ainda encenam importantes eventos históricos, como a Proclamação da República e a Revolução Federalista.

No entanto, o que aproxima os protagonistas do quarteto de romances é justamente o fato de serem todos eles, em algum momento de suas vidas, visitantes ao Sul. Provindos de diversas partes do mundo e pelas mais variadas razões, os personagens de Assis Brasil de alguma maneira acabam por aportar em terras gaúchas em momentos significativos de suas vidas e, no solo daquela região, encontram experiências definidoras de suas existências. Nesse processo, seus conflitos internos são contrapostos às características físicas, à história e aos habitantes do espaço com o qual passam a se relacionar. A singular extensão do pampa gaúcho surge, assim, como veículo de transformação, pelo qual nenhum dos personagens passa incólume. Sandro Lanari finalmente torna-se fotógrafo, ainda que para isso precise testemunhar - e fotografar - os horrores da disputa entre ximangos e maragatos; o historiador de A margem imóvel do rio aprende a vagar pelo Sul, como se em busca de uma nova identidade, confrontando a impossibilidade de apreender a história em sua totalidade; o maestro Mendanha recupera sua música perdida, embora isso lhe custe a vida; Aimé Bonpland encontra seu destino na busca pela yerba.

Para esses visitantes ao Sul, ao que tudo indica, apenas no transcorrer de uma vida inteira, no entrelugar do trânsito e no aportar em novos espaços pode brotar alguma resposta, mesmo que sempre provisória e incompleta. É preciso atravessar tempo e espaço, o espaço específico do Rio Grande do Sul, com sua história e sua cultura. Por essa insistência na região sulina, inclusive, Assis Brasil se alinha à tendência da produção literária atual de muitas vezes se debruçar sobre o espaço regional com um interesse marcadamente culturalista. Pela fatura que logra imprimir aos seus textos, foge aos estereótipos largamente convencionados como sendo característicos das culturas regionais. Com isso, em textos como os do autor, a região não surge como espaço a ser observado, mas como um complexo local de trânsito e de trocas, como ponto propício para observar, nas entrelinhas da subjetividade das personagens, um espectro mais amplo de acontecimentos.

\footnotetext{
${ }^{7}$ A aproximação que Josué Guimarães faz de sua obra com a de Jorge Amado não deixa de ser um contrassenso. Embora seja comumente vinculado a uma ideia de brasilidade, o escritor baiano sempre foi considerado pela crítica um autor regionalista e, ainda que em sua obra se possa distinguir ao menos cinco temas, conforme indica Alfredo Bosi (2011, p. 406), a narrativa de Amado dificilmente seria interpretada como representante de uma "linguagem nacional". Ou seja, nos romances de Jorge Amado sobejam elementos tipicamente regionais, seja na linguagem, seja na temática. Essa é uma das marcas evidentes que ajudam a explicar o sucesso do escritor entre os leitores.
} 
Em chave distinta, mas igualmente interessada em abordar um espaço regional marcado pelas consequências de práticas de deslocamento características da contemporaneidade, pode-se examinar a narrativa de Essa terra, romance publicado por Antônio Torres em 1976. Nele, narrase a história dos irmãos Nelo e Totonhim, personagens cujas vidas são profundamente alteradas pelos fluxos migratórios que marcaram as relações sociais no sertão ao longo do século XX. O relato da migração, que ganhou destaque em obras como O quinze (1930), de Rachel de Queiroz, ou Vidas secas (1938), de Graciliano Ramos, e assinalou a tendência neorrealista do Romance de 30, reaparece, mas com os polos invertidos, na ficção de Torres. Essa face da tradição literária regionalista, que surgiu politizada e contestatória, denunciando os resultados perversos da problemática divisão de poder no Brasil e dos processos de modernização nacional sempre prontos a construir ruínas, é reencenada em Essa terra na figura do irmão que deixa a cidadezinha do Junco e parte em direção a São Paulo, porém é forçado a retornar, anos mais tarde, apenas para cometer suicídio na terra natal.

Pensada no conjunto de uma tradição literária, a inversão proposta por Antônio Torres possui impacto não negligenciável na série literária brasileira. Representado de maneiras distintas pelos românticos, pela ficção do fin de siècle, pelos romancistas da década de 30 e recuperado em viés inesperado por Guimarães Rosa já na metade do século XX, é inegável que o sertão tenha se tornado um importante tópos literário no Brasil. Dito de modo redutor, o tema passou de uma perspectiva idealizada em seu início a uma visão progressivamente crítica conforme se desenvolveu. $\mathrm{O}$ resultado desse desenvolvimento, perceptível na obra de Torres, inaugura uma nova fase na literatura brasileira, conforme identifica Italo Moriconi, substituindo a experiência do sertanejo no sertão pela experiência do sertanejo no Sudeste. "Em Essa terra, tal experiência aparece pelo negativo, é presença ausente, assim como o próprio personagem Nelo no romance é presença ausente, narrada pelos olhos do irmão-mais-novo-que-ficou" (Moriconi, 2008, p. 8).

No entanto, talvez não seja exato considerar que, hoje, o sertão "virou periferia das grandes cidades" (Moriconi, 2008, p. 8). Na verdade, tais espaços não se confundem, embora tenham cada vez mais pontos de contato elaborados pela ficção contemporânea. Tanto na periferia urbana quanto nesse sertão marcado por contradições, essa literatura tem procurado iluminar a condição humana em face da iniquidade e, muitas vezes, da impotência. Mas enquanto a literatura da primeira metade do século XX ainda acenava com uma possibilidade de esperança, ao vislumbrar o horizonte da migração, a contemporaneidade, ciente de seus resultados reais, assinala mais um processo abortado. Tragicamente, a inversão do ciclo migratório protagonizada por Nelo não representa um reencontro com um espaço de pertencimento, uma vez que o sujeito que partiu já não é o mesmo que retorna, mas motiva toda a narração de Totonhim, pondo em exame a sua própria relação com o Junco, com o sertão, com a realidade cultural circundante. Eis como procede Essa terra, oferecendo novas modulações à tradição literária em que se insere.

\section{À guisa de conclusão}

Parece, então, pertinente inquirir como a corrente regionalista pode ter caminhado, lentamente e de acordo com o imaginário de cada época, no sentido de uma aproximação maior ao indivíduo marginalizado pelos centros a uma só vez urbanos e simbólicos. Pode ser relevante, em suma, responder em que medida a tradição regionalista se transformou a ponto de encarnar hoje uma perspectiva como aquela defendida por Edward Said, pela qual o artista e o intelectual devem dominar a cultura tal qual concebida pelo centro e possuir o capital simbólico necessário para enunciar com legitimidade, mas o fazer a partir da margem e pelo olhar de quem está à margem. Afinal, a própria Manaus de Hatoum, a Santa Fé de Erico Verissimo ou o sertão de Rosa somente são "regiões" e possuem "particularidades" por serem vistas a partir de um centro econômico, político e cultural bastante claro.

Ao que tudo indica, esse viés pode ser uma alternativa viável para examinar a literatura contemporânea com um olhar mais solidário às suas recentes modulações temáticas e formais, procurando não a encaixar em esquemas pré-concebidos de bom e ruim, mas investigando quais novas respostas ela é capaz de fornecer aos problemas que perduram. Com tal procedimento, talvez 
seja possível melhor compreender por que razões os autores brasileiros que utilizam matéria regional temem a vinculação à tradição literária regionalista. Por outro lado, essa aproximação pode se mostrar eficaz por também lançar luzes inovadoras sobre a produção literária dos autores contemporâneos, os quais, ao que parece, continuam produzindo literatura com a mesma matériaprima regional dos antecessores. Cabe à crítica, portanto, mais do que estabelecer as devidas conexões entre autores, obras e períodos literários, fornecer interpretações que deem conta de explicar o fenômeno da tradição regionalista brasileira a partir de paradigmas que recusem a necessidade de "superação" do dado regional e que desfaçam a relação de equivalência que se criou entre "Regionalismo" e "literatura de má qualidade".

Para tanto, um caminho oportuno reside na possibilidade de compreender o Regionalismo, antes de tudo, como uma tradição literária de longa duração no Brasil. Trata-se, em primeiro lugar, de reconhecer sua permanência na contemporaneidade e de investigar as modulações pelas quais vem passando. Em seguida, deve-se apreendê-lo como um rótulo que designa um conjunto de obras cuja afinidade reside em recuperar e ressignificar motivos e temas literários característicos de uma corrente literária, a partir do trabalho com espaços, tipos humanos, imagens e linguagens intrinsecamente vinculados a ela. Assim procedendo, será possível verificar que, em razão das transformações do Regionalismo no decorrer do tempo, a maneira como textos literários regionalistas se apropriam do material fornecido pela tradição igualmente sofre mutações, de modo que a ficção atual já não se apresenta utópica ou programática como nos séculos passados. Essa compreensão serviria para elucidar que a simples vinculação ao Regionalismo não restringe - tampouco amplia - o alcance de uma obra e, ainda, permitiria problematizar as próprias estruturas de valoração do campo literário.

\section{Referências}

ARENDT, João Cláudio (2015). Notas sobre regionalismo e literatura regional: perspectivas conceituais. Todas as Letras Z, São Paulo, v. 17, n. 2, p. 110-126, maio/ago.

ASSIS BRASIL, Luiz Antonio de (2002). O pintor de retratos. 6. ed. Porto Alegre: L\&PM.

ASSIS BRASIL, Luiz Antonio de (2003). A margem imóvel do rio. Porto Alegre: L\&PM.

ASSIS BRASIL, Luiz Antonio de (2006). Música perdida. Porto Alegre: L\&PM.

ASSIS BRASIL, Luiz Antonio de (2012). Figura na sombra. Porto Alegre: L\&PM.

BOSI, Alfredo (2011). História concisa da literatura brasileira. 42. ed. São Paulo: Cultrix.

CANDIDO, Antonio (2007). Formação da literatura brasileira: momentos decisivos, 1750-1880. Rio de Janeiro: Ouro sobre Azul.

CHIAPPINI, Ligia (1995). Do beco ao belo: dez teses sobre o regionalismo na literatura. Estudos Históricos, Rio de Janeiro, v. 8, n. 15, p. 153-159. Disponível em: https:/ / bit.ly/2L6BwUf. Acesso em: 3 jun. 2010.

COUTO, Mia (2010). Personagem em busca de um autor. [Entrevista a] Ricardo Prado. Carta Capital, 8 dez. Disponível em: https://www.cartacapital.com.br/educacao/personagem-em-busca-de-um-autor Acesso em: 10 abr. 2017.

CURY, Maria Zilda Ferreira (2009). Topografias da ficção de Milton Hatoum. In: RAVETTI, Graciela; CURY, Maria Zilda Ferreira; ÁVILA, Myriam (Org.). Topografias da cultura: representação, espaço e memória. Belo Horizonte: Editora UFMG. p. 41-62.

FIGUEIREDO, Eurídice (2013). Literatura comparada: o regional, o nacional e o transnacional. Revista Brasileira de Literatura Comparada, n. 23, p. 31-48. Disponível em: https://bit.ly/2rMHxhO. Acesso em: 13 jan. 2014.

FISCHER, Luís Augusto (2007). Conversa urgente sobre uma velharia - uns palpites sobre vigência do Regionalismo. Cultura e Pensamento, Brasília, n. 3, dez. 
GALVÃO, Walnice Nogueira (2008). Mínima mímica: ensaios sobre Guimarães Rosa. São Paulo: Companhia das Letras. p. 91-118.

GAMA, Rinaldo (2013). Vidas secas e outras vidas. Revista Bravo!, Caderno Literatura, ed. 191, jul. Disponível em: http://bravonline.abril.com.br/materia/vidas-secas-e-outras-vidas Acesso em: 12 out. 2013

GUIMARÃES, Josué. (1988). 3. ed. Porto Alegre: IEL, AGE/Ulbra.

HATOUM, Milton (2005). Cinzas do Norte. São Paulo: Companhia das Letras.

LAJOLO, Marisa (1998). Regionalismo e história da literatura: quem é o vilão da história? In: FREITAS, Marcos Cezar (Org.). Historiografia brasileira em perspectiva. São Paulo: Contexto. p. 297-327.

LEÃO, Allison (2011). Milton Hatoum: regionalismo revisitado ou renegado? In: CONGRESSO INTERNACIONAL DA ABRALIC, 12., Curitiba. Anais [...] Curitiba: Abralic. Tema: Centro, Centros - Ética, Estética. Disponível em: https://bit.ly/2Lb1zcJ. Acesso em: 25 ago. 2011

LORENZ, Günter (1991). Diálogo com Guimarães Rosa. In: COUTINHO, Eduardo. Guimarães Rosa (Coleção Fortuna Crítica). Rio de Janeiro: Civilização Brasileira. p. 62-97.

MARCONDES, Marleine Paula; TOLEDO, Ferreira de (2004). Espaço e preconceito nas obras de Hatoum. In: CONGRESSO LUSO-AFRO-BRASILEIRO DE CIÊNCIAS SOCIAIS, 8., Coimbra. Actas [...] Coimbra: Centro de Estudos Sociais. Disponível em: https://bit.ly/2r6pqUj. Acesso em: 19 jun. 2011.

MECKLENBURG, Norbert (2013). Regionalismo literário em tempos de globalização. In: ARENDT, João Claudio; NEUMANN, Gerson Roberto (Org.). Regionalismus - Regionalismos: subsídios para um novo debate. Caxias do Sul: Educs. p. 173-195.

MORICONI, Italo (2008). Prefácio. In: TORRES, Antônio. Essa terra. Rio de Janeiro: BestBolso. p. 7-10.

PELINSER, André Tessaro (2015). Guimarães Rosa e seus precursores: regionalismo, deslocamentos e ressignificações. 349 f. Tese (Doutorado em Estudos Literários) - Universidade Federal de Minas Gerais, Belo Horizonte.

PELINSER, André Tessaro (2017). Guimarães Rosa e o Regionalismo literário brasileiro: revisão crítica sobre um problema perene. Signo, Santa Cruz do Sul, v. 42, n. 74, p. 2-19, maio/ago. Disponível em: http://dx.doi.org/10.17058/signo.v42i74.8605. Acesso em: 21 ago. 2019.

PELLEGRINI, Tânia (2002). A ficção brasileira hoje: os caminhos da cidade. Revista de Filología Románica, n. 19, p. 355-370. Disponível em: https:/ / bit.ly/34FyKwL. Acesso em: 7 jun. 2015.

PESAVENTO, Sandra Jatahy. A temporalidade da perda. In: PESAVENTO, Sandra Jatahy; LEENHARDT, Jacques; LEITE, Ligia Chiappini M.; AGUIAR, Flávio (2001). Erico Verissimo: o romance da história. São Paulo: Nova Alexandria. p. 89-102.

POZENATO, José Clemente (2003). Processos culturais: reflexões sobre a dinâmica cultural. Caxias do Sul: Educs.

RADUY, Ygor (2006). Apontamentos sobre Guimarães Rosa e a prática historiográfica: desenraizamento e sacralização. Terra Roxa e Outras Terras - Revista de Estudos Literários, Londrina, v. 7, p. 70-80.

ROSA, João Guimarães (2001a). Ave, palavra. 5. ed. Rio de Janeiro: Nova Fronteira.

ROSA, João Guimarães (2001b). Grande sertão: veredas. 19. ed. Rio de Janeiro: Nova Fronteira.

SANTINI, Juliana (2011). A “Formação da literatura brasileira" e o regionalismo. O Eixo e a Roda: Revista de Literatura Brasileira. Belo Horizonte: Faculdade de Letras da UFMG, v. 20, n. 1, jan./jun. p. 69-85.

TORRES, Antônio (2008). Essa terra. Rio de Janeiro: BestBolso.

VERISSIMO, Erico (1995). Solo de clarineta. 20. ed. São Paulo: Editora Globo. v. 1. 